\title{
ASSESSMENT OF POWER SYSTEM SECURITY USING CONTINGENCY ANALYSIS
}

\author{
Venkatesh $\mathrm{P}^{1}$ and $\mathrm{N}$. Visali ${ }^{2}$ \\ ${ }^{1}$ Research Scholar, EEE, JNTUA University, India \\ ${ }^{2}$ Professor, EEE, JNTUA University, India \\ ${ }^{1}$ venkateshp.engg@gmail.com, ${ }^{2}$ nuisali.eee@jntua.ac.in
}

\begin{abstract}
In present scenario, the power system is becoming extensive and more multifaceted. It is important to predict the line flows and bus voltages for dissimilar operating circumstances and network topologies of a power system. Failure of any equipment's during its operation harms the reliability of the system, hence leading to outages. Cascading outages can have a catastrophic influence on power system security. Ensuring the safe and reliable operation of a power system requires assessing both the static and the dynamic operations of the power system. Transmission switching is conveyed as an optimization problem to regulate the most influential lines as candidates for the interruption. The off line analysis to predict the effect of individual incident is a tedious task as a power system contains a large number of components. A detailed security assessment is essential to deal with the possible failures in the system, its consequences and its remedial actions. The proposed method has been tested on IEEE39 bus system with various loading and outage conditions using the Mi - Power.
\end{abstract}

Keywords - Static and dynamic operations, cascading outages, reliability, Transmission Switching, Mi-Power

\section{INTRODUCTION}

In the modern era the electrical power systems are pushed to operate closer to their thermal limits due to the combination of increased energy consumption and various kinds of barriers to the extension of the existing transmission system. In the steady state security assessment of a power system, it is important to predict the line flows and bus voltages for various operating scenario and network topologies. For reliable, secure and continuous supply of electrical energy is an essential part of today's complex society.

The electrical power that can be transmitted between two locations in a network is limited by several security criteria such as voltage limits, lines thermal limits and stability limits. When power cannot be transmitted to a part of the network because of violating one or more of the mentioned security criteria, the system is said to be congested and consequently the market power problem is likely to occur [1]. Security is the ability of the system to resist any kind of the pre-selected list of contingencies without any consequences.

It is well known that power system is a complex network consisting of numerous equipment like generators, transformers, transmission lines, circuit breakers, etc. Failure of any of this equipment during its operation harms the reliability of the system, hence leading to outages. Transmission switching (TS) phenomena can be shown as economic 
benefits solutions, improve system reliability, and enhance the management of intermittent renewable resources [2].

Installation of redundant generation capacity or transmission lines is essential in order to make the system run even when any of its components fail. But, power system being dynamic in nature, does not guarantee that it will be $100 \%$ reliable. Further, such arrangement may not be cost-effective. Hence, a detailed security assessment is essential to deal with the possible failures in the system, its consequences and its remedial actions. This assessment is known as power system security assessment.

\section{Method to Solve Load Flows:}

We have different mathematical techniques used for load flow study are

1) Gauss Seidel method

2) Newton Raphson method

3) Fast-Decoupled method

\section{Fast-Decoupled Method:}

Decoupled method is a reduced form of NR method. The main advantage of the Fast Decoupled Load Flow (FDLF) as compared to the NR method is its reduced memory requirement in storing the Jacobean. There is not much of an advantage from the point of view of speed since the time per iteration of the FDLF is almost the same as that of NR method and it always takes more number of iterations to converge because of the approximation.

An important and useful property of power system is that the change in real power is primarily governed by the charges in the voltage angles, but not in voltage magnitudes. On the other hand, the charges in the reactive power are primarily influenced by the charges in voltage magnitudes, but not in the voltage angles.

\section{CONTINGENCY ANALYSIS}

"Unpredictable condition in the power system is known as contingency". The operation and control of power systems in real time require that a number of supervisory functions be executed in the Control Center. First of all, the current operating condition of the system is obtained through state estimation from real time measurements and database information. Once the base case is known, the security analysis function is carried out. [7] $-[11]$.

A power system which is operating under normal mode may face contingencies such as sudden loss of line or generator, sudden increase or decrease of power demand. These contingencies cause transmission lines overloading or bus voltage violations. Electrical power system voltage stability is receiving special attention these days. During the past two and half decades, it has become a major threat to the operation of many systems.

\section{METHODOLOGY}

Selection can be done in two popular methods they are:

\section{I). Ranking Method (or) Indirect Method}

II). Screening method (or) Direct Method

II). Screening method (or) Direct Method:

In this direct method weightage of outages is specified based on priority and overloading of transmission lines [12]. 


\section{Algorithm for list of contingencies:}

Step 1: Read the base case results.

Step 2: Select the maximum \%loaded transmission line among the base case results.

Step 3: Select $1^{\text {st }}$ line outage and run 1P1Q.

Step 4: List out the number of transmission lines overloaded.

Step 5: find the maximum \%loading of outage condition \&select the next outage of the line which is unique from the previous case and closing previous outage.

Step 6: List the total number of transmission lines which are overloaded.

Step 7: Check whether all overloaded transmission lines undergone 1P1Q method.

Step 8: Arrange all the outages in descending order

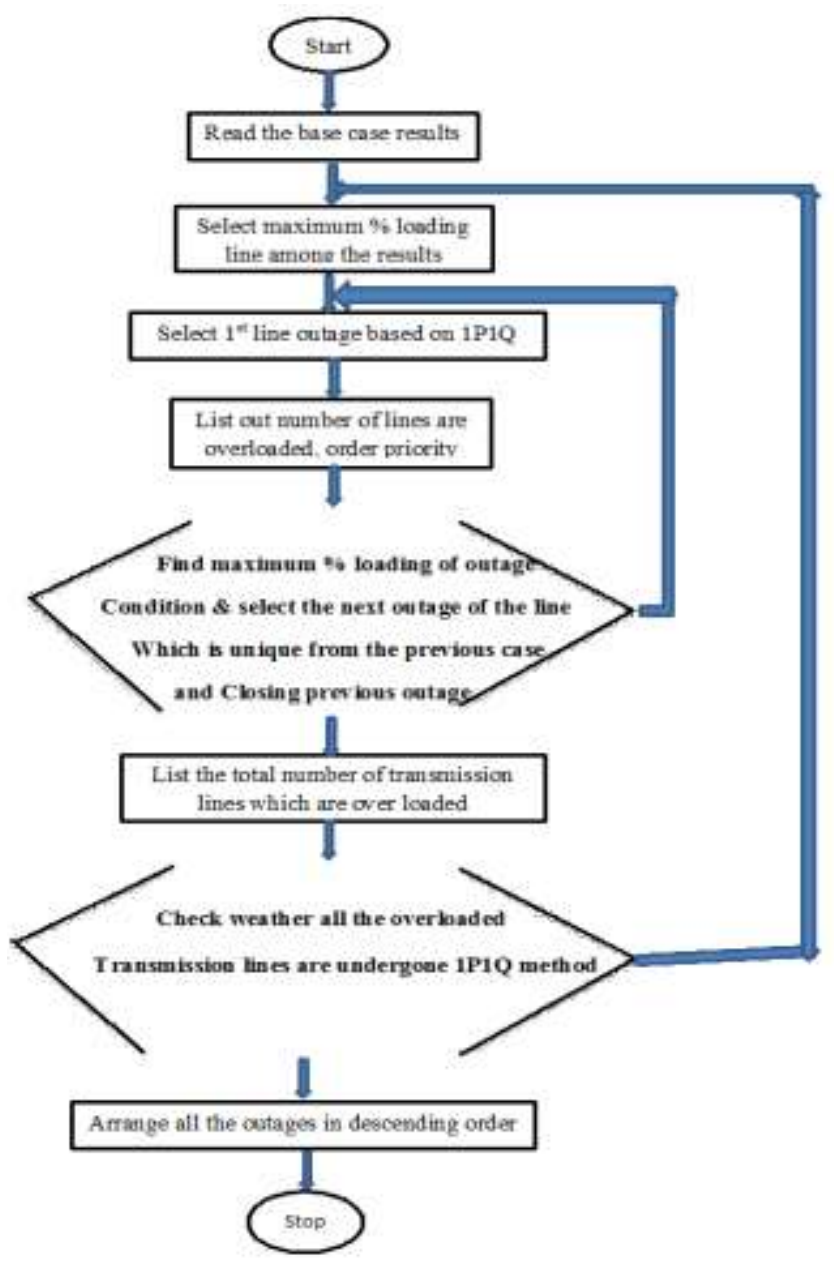

Fig. 1 Flowchart for Outages, According to their Priority

\section{RESULTS AND DISCUSSIONS}

Mi-Power software has been utilized to identify the contingences which are most severe. Mi-Power is developed by Power research development Consultants (PRDC) Private Ltd.Mi-Power is armed with robust power system engine in the backend and a lucid top-notch Windows GUI in the front-end. Approach, technique \& methodology employed are field proven \& time-tested.Mi-Power contains tool boxes like Balanced 
Load Flow, Three Phase Load Flow, Short Circuit, Transient Stability, Over Current Relay Co-ordination, Distance Relay Co-ordination Voltage Instability, Harmonic Analysis, Dynamic Stability etc. [13].

The main focus here is to perform the contingency analysis, by calculating the load flows and loading capabilites carried out using fast decoupled load flow (FDLF) under Mi-Power environment. The most severe contingency is then chosen from the contingency list and the corresponding power flows and bus voltages are analyzed for the entire system. The study has been carried out for the followingmodified IEEE-39 systems.

\section{MODIFIED IEEE-39 BUS SYSTEM:}

The system consists of overall 39 buses with 11 two winding transformers, 35 transmission lines, 19 loads and 10 generators, chosen slack bus as 39 bus [14].

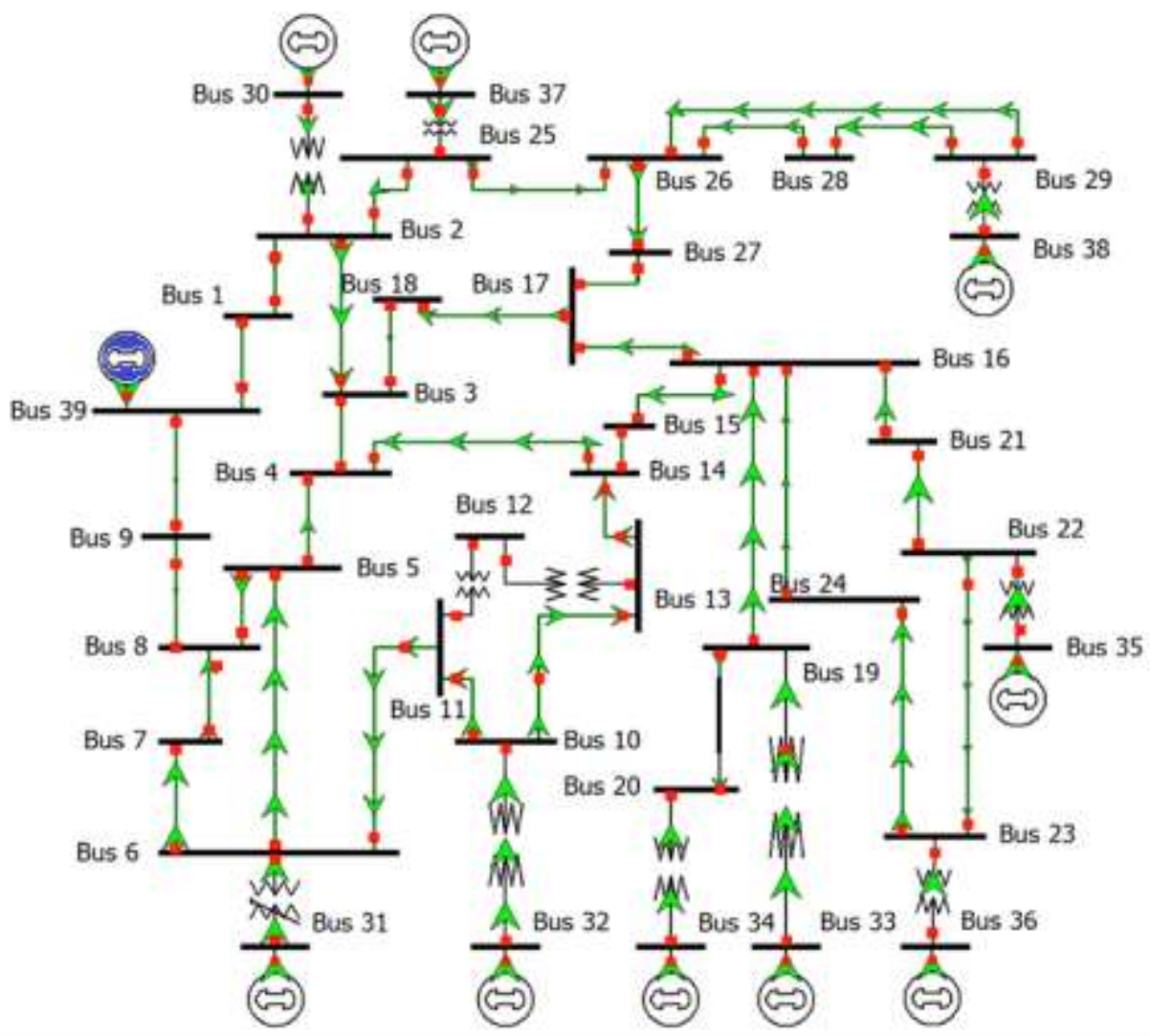

Fig 2 Modified New-England IEEE39 Bus System

As shown in Figure 2 a transformer has discarded from IEEE-39 bus system between $20^{\text {th }}$ and $19^{\text {th }}$ bus due to connectivity problem and considered it as a transmission line. If we consider it as a transformer, an ideal transformer should be chosen. Complexity and cost of the system increases. Load flow analysis are carried out based on fast decoupled load flow for the modified IEEE-39 bus system. It gives fast convergence, reliable results and requires less memory. By using the fast decoupled method we can find the power flows flowing in a system. Then we can find whether the transmission line is overloaded or not. Table II and III represent the load flow results for modified IEEE-39 bus system. 
Table I. Load Flow Results

\begin{tabular}{|c|c|c|}
\hline S.no & Voltage & Angle \\
\hline Bus1 & 1.0578 & -1.18 \\
\hline Bus2 & 1.0399 & -2.91 \\
\hline Bus3 & 1.0186 & -7.18 \\
\hline Bus4 & 0.9806 & -9.98 \\
\hline Bus5 & 0.9761 & -9.93 \\
\hline Bus6 & 0.9757 & -9.64 \\
\hline Bus7 & 0.9698 & -11.04 \\
\hline Bus8 & 0.9708 & -11.11 \\
\hline Bus9 & 1.0265 & -4.45 \\
\hline Bus10 & 0.9781 & -6.3 \\
\hline Bus11 & 0.977 & -7.43 \\
\hline Bus12 & 0.9489 & -7.2 \\
\hline Bus13 & 0.9785 & -6.84 \\
\hline Bus14 & 0.9853 & -8.02 \\
\hline Bus15 & 0.9964 & -7.21 \\
\hline Bus16 & 1.0143 & -5.22 \\
\hline Bus17 & 1.025 & -6.11 \\
\hline Bus18 & 1.0221 & -6.96 \\
\hline Bus19 & 0.9988 & 0.64 \\
\hline Bus20 & 0.9922 & -0.32 \\
\hline Bus21 & 1.0161 & -2.76 \\
\hline Bus22 & 1.0329 & 1.81 \\
\hline Bus23 & 1.0333 & 1.59 \\
\hline Bus24 & 1.0218 & -5.11 \\
\hline Bus25 & 1.0485 & -1.79 \\
\hline Bus26 & 1.0629 & -3.76 \\
\hline Bus27 & 1.0419 & -5.98 \\
\hline Bus28 & 1.0573 & -0.28 \\
\hline Bus29 & 1.0477 & 2.52 \\
\hline Bus30 & 1.0475 & -0.55 \\
\hline Bus31 & 0.982 & -9.8 \\
\hline Bus32 & 0.9831 & 1.44 \\
\hline Bus33 & 0.9972 & 8.13 \\
\hline Bus34 & 1.0123 & 4.84 \\
\hline Bus35 & 1.0493 & 6.68 \\
\hline Bus36 & 1.0635 & 9.52 \\
\hline Bus37 & 1.027 & 4.91 \\
\hline Bus38 & 1.0265 & 9.48 \\
\hline Bus39 & 1.03 & 0 \\
\hline
\end{tabular}

Table II. \% Loading

\begin{tabular}{|c|c|c|}
\hline S.no & Transmission & $\%$ \\
\hline 1 & Bus1 - Bus2 & 33.8 \\
\hline 2 & Bus1 - Bus39 & 52 \\
\hline 3 & Bus2 - Bus3 & 103.9 \\
\hline 4 & Bus2 - Bus25 & 68.2 \\
\hline 5 & Bus3 - Bus4 & 75.6 \\
\hline 6 & Bus3 - Bus18 & 14 \\
\hline 7 & Bus4 - Bus5 & 12 \\
\hline 8 & Bus4 - Bus14 & 105.4 \\
\hline 9 & Bus5 - Bus6 & 37.7 \\
\hline 10 & Bus5 - Bus8 & 46.9 \\
\hline 11 & Bus6 - Bus7 & 53.6 \\
\hline 12 & Bus6 - Bus11 & 114.5 \\
\hline 13 & Bus7 - Bus8 & 9.4 \\
\hline 114 & Bus8 - Bus9 & 91.7 \\
\hline 15 & Bus9 - Bus39 & 84.4 \\
\hline 16 & Bus10 -Bus11 & 112.3 \\
\hline 17 & Bus10 - Bus13 & 53.5 \\
\hline 18 & Bus13 - Bus14 & 54.6 \\
\hline 19 & Bus14 -Bus15 & 35.4 \\
\hline 20 & Bus15 - Bus16 & 105.5 \\
\hline 21 & Bus16 - Bus17 & 55.6 \\
\hline 22 & Bus16 - Bus19 & 89.8 \\
\hline 23 & Bus16 - Bus21 & 80.8 \\
\hline 24 & Bus16 - Bus24 & 34.6 \\
\hline 25 & Bus17 - Bus18 & 47.3 \\
\hline 26 & Bus17 - Bus27 & 32.6 \\
\hline 27 & Bus21 - Bus22 & 90.9 \\
\hline 28 & Bus22 - Bus23 & 12.2 \\
\hline 29 & Bus23 - Bus24 & 85.6 \\
\hline 30 & Bus25 - Bus26 & 38 \\
\hline 31 & Bus26 - Bus27 & 80.1 \\
\hline 32 & Bus26 - Bus28 & 42.2 \\
\hline 33 & Bus26 - Bus29 & 76.5 \\
\hline 34 & Bus28 - Bus29 & 117.3 \\
\hline 35 & Bus19 - Bus20 & 26 \\
\hline
\end{tabular}




\section{OUTAGES BASED ON \%LOADING AND PRIORITY:}

Under normal condition 6 lines are overloaded. Using 1P1Q method, contingency analysis is carried out based on \%loading of the line and Priority based technique by considering line outage distribution factor. Select the maximum \%loading transmission line, open it and perform load flow analysis. We will get another set of maximum \%loading lines. Find the maximum \%loading of outage condition \& select the next outage of the line which is unique from the previous case and closing previous outage.Repeat the procedure until all the over loaded transmission lines undergone 1P1Q method.

Table III. Ranking based on \% loading

\begin{tabular}{|c|c|c|c|}
\hline Line numbers & Lines outages & \%Loading & Ranking \\
\hline 1). L8 & 4 to 14 & $\mathbf{2 5 6}$ & 1 \\
\hline 2). L33 & 26 to 29 & $\mathbf{1 9 3 . 5}$ & 2 \\
\hline 3). L34 & 28 to 29 & $\mathbf{1 7 9}$ & 3 \\
\hline 4). L18 & 13 to 14 & $\mathbf{1 6 6}$ & 4 \\
\hline 5). L16 & 10 to 11 & $\mathbf{1 6 5 . 9}$ & 5 \\
\hline 6). L12 & 6 to 11 & $\mathbf{1 6 5 . 7}$ & 6 \\
\hline 7). L4 & 2 to25 & $\mathbf{1 6 0 . 9}$ & 7 \\
\hline 8). L31 & 26 to 27 & $\mathbf{1 5 9 . 5}$ & 8 \\
\hline 9). L3 & 2 to 3 & $\mathbf{1 5 8 . 9}$ & 9 \\
\hline 10). L17 & 10 to 13 & $\mathbf{1 5 8 . 4}$ & 10 \\
\hline 11). L5 & 3 to 4 & $\mathbf{1 5 1 . 4}$ & 11 \\
\hline 12). L20 & 15 to 16 & $\mathbf{1 4 9}$ & 12 \\
\hline 13). L21 & 16 to 17 & $\mathbf{1 3 7 . 5}$ & 13 \\
\hline 14). L15 & 9 to 39 & $\mathbf{1 3 3 . 9}$ & 14 \\
\hline 15). L14 & 8 to 9 & $\mathbf{1 3 3 . 9}$ & 15 \\
\hline 16). L19 & 14 to 15 & $\mathbf{1 3 0 . 6}$ & 16 \\
\hline 17). L25 & 17 to 18 & $\mathbf{1 2 7 . 6}$ & 17 \\
\hline 18). L2 & 1 to 39 & $\mathbf{1 1 0 . 1}$ & 18 \\
\hline 19). L1 & 1 to 2 & $\mathbf{1 0 2 . 2}$ & 19 \\
\hline 20). L10 & 5 to 8 & $\mathbf{1 0 1 . 6}$ & 20 \\
\hline & & & \\
\hline
\end{tabular}

Based on their \% loading capabilities and priority technique, rankings are assigned for every overloaded transmission line. Table 3 represents list the maximum possible outages in modified IEEE-39 bus system.

\section{CONCLUSION}

In this paper ranking is assigned for every outage condition. With the help of 1P1Q method contingency analysis is carried out. Maximum \% loadings are identified. Ranking are assigned based on \%loading and priority based technique. Techniques are 
implemented on modified IEEE-39 bus network (New-England Power System) using MiPower.20 lines undergo the outage condition in modified IEEE-39 bus system.

\section{REFERENCES}

[1] Paragmitra, “A Systematic Approach to n-1-1 Analysis for Pwer System Security Assessment”, IEEE Power and Energy Technology Systems Journal, vol. 3, no. 2, (2016) June, pp. 71-80.

[2] Mojtaba Khanabadi, Hassan Ghasemi, and Meysam Doostizadeh, "Optimal Transmission Switching Considering Voltage Security and N-1 Contingency Analysis", IEEE transactions on power systems, vol. 28, no. 1, (2013) February, pp. 542-550.

[3] Shahnawaaz Shaikh and Vijayalaxmi Lingaraddi, "Contingency Ranking and Analysis Using Mipower", International Journal of Engineering Trends and Technology (IJETT), vol. 10, no. 8, (2014) April, pp. 418-422.

[4] Shekhappa G. Ankaliki, "Contingency analysis of power system using mi-power software", i-manager 's Journalon power system engineering, vol.1, no. 4, November'13 - January (2014), pp. 29-33.

[5] Ramandip Singh, "Power System Security Using Contingency Analysis for Distributed Network", International Journal of Engineering Research \& Technology (IJERT), vol. 2, no. 4, (2013) April, pp. 1256-1261.

[6] Sandeepkaur, Amarbir Singh, Raja Singh Khela, "Load Flow Analysis of IEEE-3 bus system by using Mipower Software", International Journal of Engineering Research \& Technology (IJERT), ISSN: 2278-0181, vol. 4, Issue 03, (2015) March, pp. 9-16.

[7] Waheed A. Oyekanmi, Ghadir Radman, Adeniyi A. Babalola, Titus O. Ajewole, "Power System Simulation and Contingency Ranking Using Load Bus Voltage Index Waheed", IEEE, (2014).

[8] P. Venkatesh, "Electrical Power Systems: Analysis, Security and Deregulation", Prentice Hall India Learning Private Limited, (2012).

[9] D P Kothari, I J Nagrath, "Modern Power System Analysis", Mcgraw Hill, Third Edition, (2003).

[10] Allen J. Wood, Bruce F,Wollenberg, "Power generation, operation, and control", John Wiley \& Sons, Inc second edition, (1996).

[11] MengYue and Xiaoyu Wang, "Outage Data Collection and Parameter Estimation for an Improved Probabilistic Contigency Analysis", IEEE, (2015).

[12] Udaykumar, "Contingency Ranking in Modern Power System by Exact and Precise Method", international journal of innovative research in electrical, electronics, instrumentation and control engineering, vol. 3, Issue 5, (2015) May, pp. 229-237.

[13] Mi-Power Manual, "How to solve Mi-power", Power Research and development consultant private limited, version recorded, (2014).

[14] Ian Hiskens, "EEE PES Task Force on Benchmark Systems for Stability Controls", (2013) November 19. 
International Journal of Control and Automation Vol. 12, No. 5 (2019) 